$5-2017$

\title{
Psychological and Physiological Ramifications of Inadequate Pain Management for the Pediatric Population: Influences of professional nursing preparation
}

Genica-Jade Ocampo

Dominican University of California

https://doi.org/10.33015/dominican.edu/2017.HONORS.ST.04

Survey: Let us know how this paper benefits you.

\section{Recommended Citation}

Ocampo, Genica-Jade, "Psychological and Physiological Ramifications of Inadequate Pain Management for the Pediatric Population: Influences of professional nursing preparation" (2017). Honors Theses. 8.

https://doi.org/10.33015/dominican.edu/2017.HONORS.ST.04

This Honors Thesis is brought to you for free and open access by the Student Scholarship at Dominican Scholar. It has been accepted for inclusion in Honors Theses by an authorized administrator of Dominican Scholar. For more information, please contact

michael.pujals@dominican.edu. 


\title{
Psychological and Physiological Ramifications of Inadequate Pain Management for the Pediatric Population: Influences of professional nursing preparation
}

\begin{abstract}
Pain management in the pediatric population is an intricate process and many existing factors contribute to inadequate pediatric pain management. Research suggests that the preparation for the nursing profession remains unsatisfactory in managing pain experiences for pediatric patients. Nurses are essential in assessing and relieving pain in pediatric patients. It is imperative to research what determinants of professional nursing preparation influence effective pain management for the pediatric population. Additionally, how nurses describe their educational or professional development of effective pain management including the psychological and physiological aspect of undermanaged pain need to be addressed. This study is being conducted through a mixed methods design and will follow quantitative research methodologies. Due to the contents of this research, this Honor's senior thesis will utilize collaboration of a pilot study and a non-experimental design. The overview of the results revealed that nurses agreed they were prepared in both their educational and professional development to manage pediatric pain. Overall, nurses felt they obtained a high level of nursing knowledge and self-efficacy, but also agree that there is a continued need for more resources to support their nursing care in pediatric pain management.
\end{abstract}

Document Type

Honors Thesis

Degree Name

Bachelor of Science

Department

Nursing

First Reader

Luanne Linnard-Palmer, EdD, RN

Second Reader

Andrea Boyle, PhD, FNAP

Keywords

Pediatrics, Nursing, Pain Management

Subject Categories

Medicine and Health Sciences | Nursing | Pediatric Nursing

This honors thesis is available at Dominican Scholar: https://scholar.dominican.edu/honors-theses/8 
Running Head: PSYCHOLOGICAL AND PHYSIOLOGICAL RAMIFICATIONS OF

INADEQUATE PAIN MANAGEMENT AND NURSING PREPARATION

Psychological and Physiological Ramifications of Inadequate Pain Management for the Pediatric Population: Influences of professional nursing preparation

By

Genica-Jade Cruz Ocampo

Submitted in partial fulfillment of the requirements of the Nursing and the Honors Program Dominican University of California 2017

First Reader: Dr. Luanne-Linnard Palmer Department of Nursing

Second Reader: Dr. Andrea Boyle $\quad$ Department of Nursing

Honors Director: Dr. Gigi Gokcek Department of Political Science/International Studies 


\author{
Abstract \\ Pain management in the pediatric population is an intricate process and many existing \\ factors contribute to inadequate pediatric pain management. Research suggests that the \\ preparation for the nursing profession remains unsatisfactory in managing pain experiences for \\ pediatric patients. Nurses are essential in assessing and relieving pain in pediatric patients. It is \\ imperative to research what determinants of professional nursing preparation influence effective \\ pain management for the pediatric population. Additionally, how nurses describe their \\ educational or professional development of effective pain management including the \\ psychological and physiological aspect of undermanaged pain need to be addressed. This study is \\ being conducted through a mixed methods design and will follow quantitative research \\ methodologies. Due to the contents of this research, this Honor's senior thesis will utilize \\ collaboration of a pilot study and a non-experimental design. The overview of the results \\ revealed that nurses agreed they were prepared in both their educational and professional \\ development to manage pediatric pain. Overall, nurses felt they obtained a high level of nursing \\ knowledge and self-efficacy, but also agree that there is a continued need for more resources to \\ support their nursing care in pediatric pain management.
}


PAIN MANAGEMENT AND NURSING PREPARATION

\section{Table of Contents}

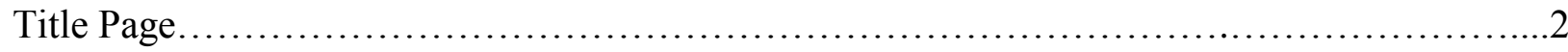

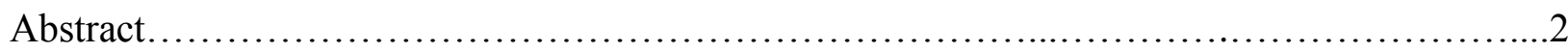

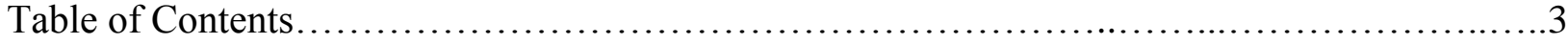

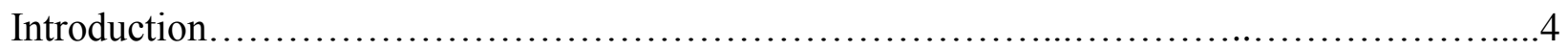

Nursing Problem Statement..................................................................

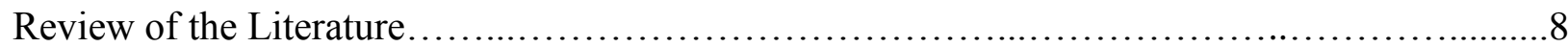

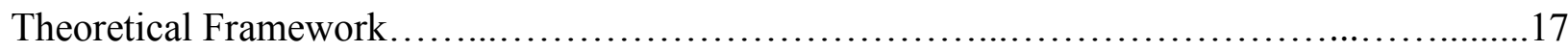

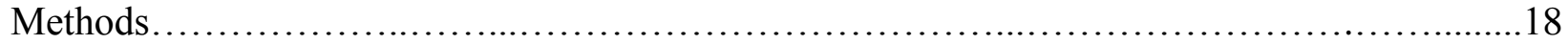

Results......................................................................., 22

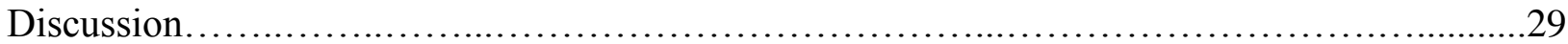

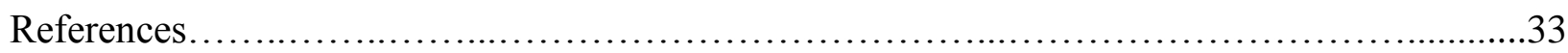

Appendix A: Letter of Introduction to Study Participants.................................. 36

Appendix B: Letters of Consent to Organization........................................... 37

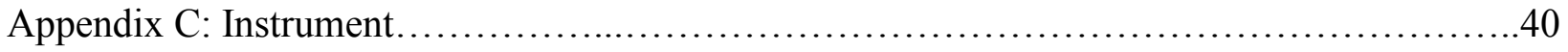




\section{Introduction}

Pain is a personal sensation of physical agony that is often caused by injury or disease. In 1968, Margo McCafferey, a registered nurse, created a universally standardized clinical definition of pain as "whatever the experiencing person says it is, existing whenever he says it does" (Giddens, 2012, p.270). Although measuring pain is not a linear process, and understanding pain is abstract, it is a domain treated with professionalism and high-standardized care in the healthcare profession. If pain remains unresolved or prolonged, it heightens to more than just a bothersome experience because it can directly impact the health of an individual. Unmanaged pain can cause both negative psychological and physiological effects. Many generalized harmful effects are associated with unrelieved pain including increased stress, weakening of the immune system, instability in major organs of the body including the heart, lungs, gastrointestinal tract, and genitourinary tract, interruption of metabolic and developmental processes, and continued development of lower tolerance of pain (Giddens, 2012, p. 272). Pain management is essential to promoting health, well-being, and healing in healthcare.

One essential component to understanding pain is to comprehend that each individual handles pain differently depending on pain perception, tolerance, situation, values, and culture (Giddens, 2012). However, the consideration of age often goes under looked as affecting pain management. For example, the assessment and management of pain in the pediatric population is handled differently than the adult population. For instance, if age and levels of development are appropriate, both pediatric and adults may have their pain measured through a numerical system of rating their pain from a zero to a ten with zero being no pain and ten being the worst pain possible. However, when pediatric patients are not developmentally capable to report their pain, pediatric behavioral assessment tools are incorporated into assessment to mobilize better acknowledgement of pain in pediatrics. There are an assortment of behavioral pain assessment 
tools for pediatrics specified to age and competencies. The most common pain assessment tool used in pediatrics is the FLACC Pain Assessment Tool, which measures behavior through categories of facial expression, leg movement, body activity, presence of crying, and consolability (Hockenberry, 2013, p. 147). A variety of both objective and subjective pain assessment tools are available and utilized by team members as children display physical characteristic of pain differently than adults.

Part of the reason why inadequate pain management in the pediatric population is a continued health problem is because children react to and communicate their pain experiences differently. It must be set in mind that children are still on a continued pattern of growth and development, and the way they present their pain may not seem as definitive as fully developed adults. Children present with pain responses and experiences that can be complex to comprehend and examine; however, there are multiple resources that are available to nurses to support measuring the multidimensional relationship of pain in pediatrics. Initiative must be taken to further research the variables that heighten the disconnect of inadequate pain management in pediatrics. There are many areas where pain management for the pediatric population needs improvement.

\section{Nursing Problem Statement}

There is a lack of knowledge concerning pediatric pain management and more effort needs to be taken to understand the factors that affect this ordeal. In 2000, the developer of the Pediatric Nurses' Knowledge and Attitudes Survey (PNKAS) discovered through research that the lack of knowledge to proper pain management in pediatrics served to be a significant barrier to patient care (Bice, 2012). Pain is a subjective experience, and it potentiates to present differently in pediatrics as the experience of pain occurs during a critical period of development biologically, socially, and mentally. The American Academy of Pediatrics and the American 
Pain Society (AAP \& APS, 2001) jointly defines pain as attributing to "sensory,

emotional, cognitive, and behavioral components that are interrelated with environmental, developmental, sociocultural, and contextual factors" and pain is a negative stimulus that strongly inflicts suffering to the pediatric population (p.793).

Nursing practice encompassed around pain management is a critical and professional responsibility. As addressed by the International Association for the Study of Pain (IASP, 2005), members define pain management as a basic fundamental human right. Pain continues to be the most prevalent problem for the inpatient pediatric population. Kozlowski et al. (2014) determined that in the United States, $86 \%$ of pediatric hospitalized patients experienced pain as an essential problem. Research suggests that the pediatric population often deals with less than optimal pain management. According to Stevens et al. (2014) advancement has taken place on extensive research and implementation of policies and guidelines, yet many hospitalized children experience pain that remains undertreated. The inadequacy of pain control in pediatrics often surfaces in acute pain management caused by injury or illness and pain related to procedures.

As inadequate pain management of the pediatric population continues to be an unresolved health concern, it leaves room for presence of heightened adverse effects and complications targeted at this population. The significance of pain control is vital within the healthcare profession because there are various negative ramifications that attribute to inadequate pain management. AAP and APS (2001) characterize pain as an adverse stimulus that provokes anxiety, avoidance, fear, future decreased pain tolerance, negative somatic symptoms, and parental distress. In 2007, Brennan, Carr and Cousins recognized that untreated pain in children can lead to biological complications including respiratory complications, persistent hyperglycemia, delayed wound healing, increased sensitivity to the inflammatory response, attention deficiencies, behavioral disorders, and chronic pain syndromes. The purpose of 
pain control in the pediatric population reaches beyond resolving temporary suffering, but preventing future negative outcomes as well. IASP (2005) confirms that experiencing inadequate pain control early in life has permanent detrimental effects on social and physical development, future pain experiences, and family processes. Inadequate pain management not only affects the child directly, but it can also have lasting impacts that follow them into adulthood and affect their interpersonal relationships with family, friends, and professionals of healthcare. If the pediatric population remains victimized to the negative outcomes of insufficient pain management, it will directly affect their motivation to continually manage their health and optimize the best quality of life throughout their lifespan.

The nursing profession must take part in directly impacting why inadequate pain management in the pediatric population remains undertreated, misunderstood, and neglected. The professional responsibility of nurses is to implement the nursing process within their practice through overseeing pain management by the means of assessment, diagnosis, planning, implementation, and evaluation. The American Nurses Association (2001) specifically reports that nurses have an ethical duty to continually assess for pain, plan to consider both pharmacological and non-pharmacological methods for pain management, implement the prioritized plan, and evaluate the effectiveness of pain management to either continue or improve the strategies taking place. To better establish the nursing process to support pain management, nurses need to further understand what components affect the relationship between the nursing process and inadequate pain management. One way to prioritize pain management in the pediatric population is to further analyze the multidimensional factors that influence the inadequacy of pain management. The proposition of this Honor's Thesis project is to utilize the accumulated research to further support the necessity to investigate the depth in understanding of the determinants of pain management in the pediatric population. This can be done by 


\section{PAIN MANAGEMENT AND NURSING PREPARATION}

investigating the influence of nursing preparation related to education, and professional

development.

\section{Introduction}

\section{Review of the Literature}

There are a variety of existing factors that influence insufficient pain management in the pediatric population. This review of the literature focused on four main concepts that influence inadequate pediatric pain management, and is based on research taken over a 10-year time span. There are a multitude of factors and relationships that affect the ability to provide adequate pain management. The four main concepts are as follows; patient characteristics and perspectives, pharmacological and non-pharmacological interventions, reassessment, intervention, and a multidimensional approach, and nurses' attitudes, knowledge, and beliefs.

\section{Patient Characteristics and Perception}

Many of the studies addressed a commonality of acknowledging patient characteristics as influencing the pain perception, and affecting the pain management process as a whole. In "Pain Beliefs Predict Pain Intensity and Pain Status in Children: Usefulness of the Pediatric Version of the Survey of Pain Attitudes" by Miró, Huguet, and Jensen (2014), their objective focused on the hypothesis that children's' attitudes and beliefs influence the pain experience. They conducted their study on a population size of five hundred and sixty-one school children between the ages of 8 to 16, acquired their information through tedious consent from the school and parents, and they categorized their findings based on social and demographic characteristics. The researchers gathered information through using Peds-SOPA, a proven comprehensive pediatric survey of pain attitudes, and interviewed the children individually at the school. The interview process collected information regarding social demographics, children's' attitudes towards pain, current status of pain, presence of disability, and the information was sorted through statistical analysis. Their study determined a high correlation between the Peds-SOPA measurement of attitudes and 
pain related outcomes. Specifically, low scores on controlled pain beliefs were associated with higher pain intensity levels, and the Peds-SOPA scores showed evidence of sex and age-specific differences. In their discussion, they highlight that understanding pain beliefs leads to understanding the pain experience, statistical significance demonstrated that boys were more entrusting than girls of having their pain resolved, and younger children viewed themselves as having more control of their pain. As the study vigilantly controlled for age, sex, and other variables, they recommend further research into cultural assessment as improving understanding the pain experience in children. Overall, this study highlighted the importance of validity, reliability, and consideration for diversity in implementing pain assessment instruments to improve children's ability to cope and perceive pain.

Kozlowski et al. (2014) aimed to analyze the prevalence of pain, and patterns of pain management practices in pediatric patients who were hospitalized. The sample consisted of a population of 200 pediatric patients ranging between 7 to 21 years of age. Through Institutional Board Review approval, and parental and patient consent, four nurse practitioners and one research clinical coordinator collected information through a prospective chart review data collection tool designed by the investigators. The information was categorized into demographics, presence and prevalence of pain, pain assessment, analgesics, side effects of therapy, and satisfaction. They organized the information collected by summary statistics with use of mean, standard deviation, range, frequency, and proportions; their models were formulated as two factor analyses of variances. Their results proved that $86 \%$ of the population had an identified pain source; there was a statistical association between pain score and gender, age, and culture, and there was an identified existing association between patient characteristics and opioid consumption. Their study determined that there is a high prevalence of pain in hospitalized children and that age, gender, and race influenced the pain experience. Variability in 
patient characteristics influence children's different presenting complaints of pain and the study identified patient related risk factors that attribute to pain.

\section{Pharmacological and Non-pharmacological Nursing Interventions}

In the knowledge that encompasses inadequate pain management, research also looked at both the pharmacological and non-pharmacological interventions used for pain management in the pediatric population. In one study by Bahorski et al., published in 2015 and entitled, "Mitigating procedural pain during venipuncture in a pediatric population: A randomized factorial study, " the researchers identify that a large portion of the pediatric population receive less than optimal management of pain related to procedures with the goal to examine how different preparatory interventions affect the perception of pain. The pediatric population studied was collected from a non-profit regional hospital based in the southeastern area of the United States and consisted of 173 children with the age range between 18 months to 17 years of age. The study was approved by the hospital's IRB, and conducted through a quasi-experimental, 3 by 4 factorial design. The participants were randomly assigned to one of three interventions including distraction, topical anesthetic ointment, and vibration; their pain scores were strategically assessed. The study's results revealed that there were no statistically significant differences between the three different intervention groups, but they all contributed to controlling pain. Overall, the study ends with discussing the importance of having multiple effective pain relief measures to support empowering both children and their parents to cope with pain and support a positive longitudinal outcome of medical experiences.

One study that looked at non-pharmacological interventions for pediatric pain management was the "Integrative Care Therapies and Pain in Hospitalized Children and Adolescents: A Retrospective Database Review” written by Cotton et al and published in 2014. Specifically, this study examines the effectiveness of complementary and integrative therapies in management of 
pain for the pediatric population. The population consisted of 519 hospitalized children and adolescents treated by integrative therapists for pain and or anxiety; the integrative pain therapies included massage therapy and healing touch. To conduct this study, the researchers used a retrospective chart review of inpatient clinical databases documented by integrative care therapists over a year. They attained IRB approval from the Cincinnati Children's Hospital Medical Center, did not attain parental consent as the data was collected retrospectively from an electronic health record, and thoroughly organized the data informatics. During the data collection process, they looked at the relationship between pre-treatment and post treatment pain scores of the integrative therapies implemented. The results revealed that there was a positive association between decreased pain scores and integrative therapies. Also, the results indicated that relaxation scores lowered from the preparation stage of therapy to the post stage of therapy, indicating that the patients presented to be more relaxed after the use of integrative therapies. The study then discussed that although utilization of integrative therapies is present within the hospital community, it is mainly influenced by professional and patient demand rather than evidence-based practice. Understanding the efficacy and effectiveness of integrative therapies plays an important role in pain management as it presents to significantly decrease pain and improve relaxation.

In another study that looked into nursing interventions and treatment of pain management through observation is “Children's nurses' post-operative pain management practices: An observational study conducted" by Twycross (2007). In her observational study that looked into both structured and unstructured data, Twycross aimed to examine how nurses implement post-operative pain management in children and whether or not practices of pain management were adherent to relevant best practice guidelines. The study was approved by the Local Research Ethics Committee, all participants were informed of their anonymousness for 
participation and gave consent, and the nurses, families, and patients were all informed that the observer was conducting research regarding methods nurses used to manage pain in children. The population studied consisted of 13 registered nurses who were continuously observed for 5 hours each shift, with each nurse assessed between 2 to 4 shifts. The researcher shadowed the nurses and acted as strictly an observer for a total of 36 shifts. The results revealed that the nurses did indeed administer analgesia when a child directly complained of pain, but most of the nurses demonstrated pain management practices that did not adhere to updated best practice guidelines. The results revealed that a pain history and medication management of pain were not usually assessed, little evidence revealed that analgesia medications were given by means of prophylaxis, simple non-drug methods were not found to be implemented regularly, and minimal parent involvement was observed in the children's pain management. This study is limited by its small sample size; however, it does recognize how nurses actually and realistically approach pain management in real time. This study identified that there is a gap between actual pain management practices in the pediatric population and the implementation of evidence-based guidelines (Twycross, 2007).

\section{Reassessment and Multidimensional Approach}

Many research studies suggested that areas of nursing are lacking, including reassessment and the use of a multidimensional approach; this negatively contributes to the inadequacy of pain management in the pediatric population. In one study published in 2016 by O'Neal and Olds entitled "Differences in Pediatric Pain Management by Unit Types," the purpose was to determine different types of pain management strategies by unit type by comparing different units on assessment, intervention, and reassessment, and analyzing different assessment tools and means of intervention. The University of Kansas Medical Center Human Subjects Committee approved this study, which utilized a cross-sectional design and secondary analysis of data 
acquired in 2013 by the National Database of Nursing Quality Indicators. The sample included 984 pediatric units in 390 hospitals and data was collected through a retrospective chart review based on type of pain assessment tool used, presence of pain, and interventions and reassessment. The findings revealed that of the population studied, $99.6 \%$ of patients were assessed for pain, the most commonly used assessment tool among all units was the Faces, Legs, Activity, Crying, and Consolability (FLACC) Scale, and although assessment was performed routinely, interventions and reassessment were weak and minimal. Although the study was limited to a retrospective chart review, the study further suggests that although initial pain assessment is universally practiced among the nursing profession, the relationship between implementation and reassessment should also be universally practiced. O’Neal and Old concluded their study by acknowledging that as pain strongly affects levels of stress and recovery, it is important to analyze where gaps are present in pediatric pain management to further reach the ultimate goal to get pediatric pain management well controlled.

One study that looked into the content of a multidimensional approach of pain management in pediatrics was "Nurses' Report of In-hospital Pediatric Pain Assessment: Examining Challenges and Perspectives, ” published in 2015 by Zisk-Rony, Lev, and Havin. The goal of the study was to examine how nurses handled pain management in hospitalized children. Approval from the ethics committee of the hospital in use took place, and the sample population consisted of all nurses from the eight pediatric units in the unanimous hospital that voluntary participated. It was noted that the hospital served a pediatric population characterized by diversity. A cross sectional study was done on pediatric nurses. No validated instrument to assess nurses' practice of pain management existed, thus an instrument of assessment was created and used based on clinical experiences and sources of literature; the data was collected by nurses voluntary and unanimously filling out the questionnaire. Results exhibited that $86 \%$ of 
the nurses relied on their own impressions to determine the child's pain, $75 \%$ of the nurses rarely or never used pain scales for assessment over a two week period, 58\% reported using some other method of pain assessment, $69 \%$ depended on parents' report of the child's pain even if the child could communicate, but $90 \%$ of the nurses agreed that involvement of the parents and family in pain assessment was important (Zisk-Rony, 2015). The study identified that nurses tend to underestimate the level of pain a child experiences and that nurses do not often use multiple methods of pain assessment. Zisk-Rony, Lev, and Havin (2016) concluded that using a multidimensional method of pain assessment including the child's report of pain, inclusion of parental observations, and the nurse's assessment of pain, can lead to thorough assessment thus promoting optimal management of pediatric pain.

\section{Nurses' Knowledge, Beliefs, and Attitudes}

Much of research supported that before nurses can deal with improving pediatric pain management, they must first come to recognize their own values and perspectives. One study that closely monitored the nurses' personal relationships of management of pain in the pediatric population was, "Relationship Between Knowledge, Attitudes, and Self-Efficacy of Nurses In the Management of Pediatric Pain, " published in 2013 by Stanley and Pollard. According to Stanley and Pollard (2013), a nurse's attitudes and beliefs directly impact the nurse's ability to sufficiently provide adequate pain management. The purpose of their study was to examine nursing knowledge, attitudes, and self-efficacy related to pediatric pain management. This study received IRB approval and the population consisted of twenty-five pediatric nurses that worked at regional hospitals. Participation was voluntary and participants were asked to complete two research questionnaires, the Pediatric Nurses' Knowledge and Attitudes Survey Regarding Pain (PNKAS) and the Nurses' Self-Efficacy in Managing Children's Pain. All relevant data went through the process of analysis using the Statistical Package for the Social Sciences (SPSS) and 
the version type was 18 , summary statistics, the Pearson correlational, and the t-test. The findings revealed that $66.6 \%$ of the questions were answered correctly on the PNKAS referring to knowledge-based information, participants overall reported a relatively high level of self-efficacy in pain management pertaining to the pediatric population, and no statistical relationship was revealed between number of years of experience and measurement of knowledge (Stanley, 2013). Based on the findings indicated, Stanley and Pollard discussed that nurses hold on to a high level of self-efficacy of pain management in pediatrics without a corresponding high level of knowledge of pain management practices (2013). These researchers suggested that more research needs to be allocated into investigating education on pain management in pediatrics, and assessment on effectiveness of educational practices regarding pediatric pain management.

One study that examined the nursing perspective on barriers to adequate pain management was “Nurses' Views About the Barriers and Facilitators to Effective Management of Pediatric Pain” by Twycross and Collins (2011). The objective of this study was to identify the nurses' perspectives relating to several factors of pediatric pain management including the quality of pain management and assessment, barriers, and usefulness of hospital guidelines. Before the study was conducted, the researchers contacted the local Research Ethics Committee to seek ethical approval, but were informed that ethical approval was not needed for this study; participants were also informed that there was no correct or incorrect answer, but rather the purpose was to identify different viewpoints. The sample consisted of 30 nurses who took part in focus groups and they answered a flipchart of key questions by addressing their views. All the data was processed and analyzed by means of the principles of content analysis. The results identified 5 common themes including pain assessment and management practices, child and parent involvement in pain management, barriers to assessing and managing pain, helpful 
interventions for nurses, and the content of the hospital guidelines. The depth of the results revealed that nurses reported using several methods for pain assessment; nurses revealed that they provided optimal communication with parents on pain management, nurses disclosed that hospital guidelines proved to be useful, and reported barriers related to the relationship between the child and parent, nurses and medical staff, and organizational attributes. Overall the nurses reported lack of adequate time, pressures of the heavy workload, lack of staff, inadequate pain medication supply, and parents not reporting or over exaggerating their child's pain level as barriers to providing optimal pain management. Twycross and Collins (2011) concluded their study by identifying that nurses need to be more multifactorial in proactively managing pediatric pain and that knowledge deficits exists among nurses and other professional staff about pediatric pain management.

A second study that determined nursing beliefs related to pain management was "Nurses' Beliefs Regarding Pain in Critically Ill Children: A Mixed-Methods Study" published in 2016 and created by LaFond et al. The purpose of this study was to provide an up to date and multiplex standpoint on evaluation of nursing beliefs related to pain in children who are critically ill. Before data collection, this study attained IRB approval and secured a population of 40 nurses as the subjects of study through participating PICUs that served to be involved in the study participation. The research conducted was based off a convergent parallel mixed-methods design, descriptive statistics were incorporated to analyze nursing demographics, and nurses that volunteered were given questionnaires and interviews, which were compared, to determine the extent of the nurses' views and beliefs on pain management. The results revealed that common beliefs that were not true related to physical determinants as dominating pain assessment, and the knowledge of pharmacology of intravenous opioids. In addition, the results indicated that nurses believed in confirming pain score with observed behavior, attributing the pain score to what the 
child exactly reports, the necessary initiative to address pain, concerns related to opioid administration, and the requirement to start interventions slowly and at low levels. The study suggested that practice guidelines should promote safe medication management, while also not miscommunicating that opioids should be given as a final resort intervention. Guidelines based on evidence based research need to address a balance between unrelieved pain management and those at risk for opioid administration, and nursing practice administered through knowledge and teaching needs to be better supported.

\section{Summary}

There have been multiple investigations conducted to explore determinants of the lack of adequacy of pain management in the pediatric population. The literature review reinforces that the multifactorial components of inadequate pain management are interrelated and come from complex systematic relationships between patients and their families, nurses, and clinical knowledge. Additionally, the multifactorial components that present to influence inadequate pain management include the patient's perspective, the need to collaboratively implement both pharmacological and non-pharmacological interventions, continued attempts of reassessment of pain, and the nurses' self-efficacy and knowledge related to pain management. The objective of the pilot study at hand will help quantify the accuracy of the research provided.

\section{Theoretical framework}

A nursing theoretical framework that encompasses the orientation of this study is Jean Watson's Nursing Theory of Human Caring. This distinct nursing theory serves as guideline and highlights recommendations for nurses to provide compassionate optimal care in dealing with the complexity of not only the human body, but also the human mind and emotions. Watson advocated that optimal practice of care in nursing requires consideration of holistic health as each patient is an individualized and valuable living being (Petiprin, 2016). Lack of adequate 
pain management is debilitating towards human well-being and optimal function, and nurses must consistently be motivated to show compassion towards the patients in pain, and genuinely care to assist in subsiding the pain experience of their patients. This theoretical approach appropriately recognizes that pain management is part of providing holistic health.

Jean Watson created seven assumptions and ten primary carative factors to define the science of caring. Three prominent assumptions that fall in relation to pain management is that care provides to the human needs, the nurses' ability to care provides patient self-determination and promotes potential, and the science of caring naturally coexists with curing (Petiprin, 2016). If pain is left to linger in the patient, provision of care for human needs remain unmet and the patient's motivation and highest potential of health and happiness can remain defeated. As caring coexist with curing, pain must inevitably be cared for in order to completely cure a patient. Some of Watson's carative factors that interrelate to pain include sensitivity to self and others, acceptance of both positive and negative feelings, problem-solving with a caring mindset, and acceptation of existential-phenomenological forces. (Petiprin, 2016). Pain is a phenomenological aspect of humanity that can easily go under recognized, especially in the pediatric population. The nursing profession must take responsibility in acknowledging the potential presence of pain, accepting how each individual patient feels about their pain experience, and set goals to genuinely care for the patient by doing their functional best to eradicate suffering and provide relief from the pain experience. Overall, Watson's theoretical framework of caring promotes that nursing must be encompassed of constant intuition of the pain response; continuous caring to manage pain is vital to further promote holistic health across the lifespan.

\section{Methods}

In the United States alone, $86 \%$ of the hospitalized pediatric population face pain as an 
essential challenge in their healthcare experience (Kozlowski et al, 2014). Nurses are heavily involved in overseeing pediatric pain management. The research revealed that there are many areas of nursing care that insufficiently do not meet the needs of pediatric patients regarding decreasing and resolving their pain experience. Challenges of nurses in managing pediatric include lack of educational exposure, underestimation of levels of pain in children, and inconsistent use of multiple modes of pain assessment available (Zisk-Rony et al., 2016). Prior to sufficiently managing pediatric pain, nurses are responsible to be consciously aware of their level of knowledge, values, perceptions, strengths, and weaknesses on the subject matter. The purpose of this Honor's senior thesis project is to answer the two following research questions:

1. What determinants of professional nursing preparation influence effective pain management for the pediatric population?"

2. How do nurses describe their education or professional development of effective pain management concerning the psychological and physiological aspects of undermanaged pain?

\section{Research Design}

The methodology of this study will follow a quantitative descriptive design. Based on the contents of this Honor's senior thesis, the research will follow a trajectory of a pilot study using a non-experimental descriptive design.

\section{Sampling}

Due to the nature of this Honor's senior thesis, the sampling procedure for this research study was primarily focused on a convenience sampling method. In addition, this research acquired its sample population through snowball sampling. Participants were encouraged to reach out to their colleagues, and known pediatric nurses in their community. Due to the circumstances of the acquisition of the population, the sample size for this pilot study will range between 15 to 45 study participants. 


\section{Sample/Population}

The sample of the population that was studied focused on pediatric nurses working across the Bay Area from a multitude of clinical settings. Clinical settings included Tamalpais Pediatrics Clinic and My Friends Pediatric Day Healthcare Center. Pediatric nurses who are members of Rho Alpha Chapter of Sigma Theta Tau International Nursing Honor's Society and the Northern California Chapter of the Society of Pediatric Nursing were requested to participate. In addition, the sampling procedure consisted of pediatric nurses known to the researcher in the community. Specifically, the sample consisted of pediatric nurses who have had active nursing practice in pediatrics within the last ten years or are currently employed as practicing pediatric nurses in the community.

\section{Instrument}

The measurement and instrument of choice for this study included a qualitative descriptive design. There are no existing professional measurement instruments that measure the nurse's perception of preparation for pain management in the pediatric population; thus, the researcher has provided a newly created instrumental tool to thoroughly conduct research for the topic at hand. The instrument measured demographics for statistical purposes. A Likert-type five point scale ranging from strongly agree to neutral to strongly disagree was utilized to determine levels of satisfaction in multiple areas of preparation for pediatric pain management; these preparatory areas of the nursing profession for pediatric nurses include educational preparation, professional development, personal values, and self-efficacy and knowledge. Also, each separate category of level of satisfaction related to nursing preparation included a fill in section where participants were asked to describe and list further details and examples related to pediatric pain management. In the sections where the participants are asked to list or describe information further, they are asked to input a minimum of three examples per category. Some 
categories also included close-ended questions with the response of yes or no to further support analysis and understanding of the topic at hand. This researcher created instrument remained available in two different formats, a paper copy survey and an online survey; however, all the questions will remain the same for both surveys.

\section{Validity}

The quantitative times series designated instrument created by the researcher required approval and critical analysis from a minimum of two qualified nurses with doctoral degrees in the nursing profession. All changes, edits, and suggestions by the nursing professionals were incorporated. This research study was supported by approval from the International Review Board approval of Dominican University of California.

\section{Procedures}

- The clinical facilities were consulted to give consent to their directors, and approved to anonymously allow their staff members to voluntarily participate in this study.

- The presidents of the nursing organizations included provided consent to anonymously allow their staff members to voluntarily participate in this study.

- Nurses in the community known to the researcher were directly contacted by the researcher via phone contact, email, or in person to request permission for participation.

- Once approval conditions were met, the instrument of this research will be distributed by two methods depending on access to the subgroups. The first method of distribution was a paper copy format of the survey, and the second method of distribution was an online version of the survey.

- To effectively and efficiently acquire an appropriate sample size, the clinical based setting were provided with paper copy surveys dropped off at their facilities by the researcher for their convenience, and were picked up two weeks following the initial 
drop off. Those who took the survey consisted of nursing staff at these clinical facilities that voluntarily participate.

- To effectively and efficiently acquire an appropriate sample size, the subjects acquired through the professional nursing organizations were emailed an online version of the survey through a website link, and were informed of a deadline of when all surveys must be submitted by.

- As nurses in the community known to the researcher were given options of distribution, the researcher was responsible for either directly picking up surveys after a maximum of a two-week period, or enforcing a deadline for submission for those who participate through the online survey.

- After all instruments has been distributed, completed, and returned back to researcher, the researcher began the process of data collection, analysis, and determination of trends and patterns within the instruments in terms of similarities and differences.

\section{Analysis}

The contents of this study underwent descriptive and interferential statistical analysis. This includes monitoring range and frequency for the demographic variables. The findings were also assessed through the means of grouping the data based on level of agreement or disagreement with the subject matter. Lastly, open-ended questions were recognized into groups as topics repeated at least once between participants.

\section{Results}

\section{Sample Characteristics}

Eighteen nurses $(n=18)$ with current or prior experience in pediatric nursing participated in the study. From the sample, five participants $(n=5)$ were between the ages of 20 to 30 years of age, nine participants $(n=9)$ were between the ages of 31 to 50 years of age, three participants 
$(n=3)$ were between the ages of 51 to 65 , and one participant $(n=1)$ was over the age of 65 years old. The sample consisted of all female participants with the majority of participants with a bachelor's degree $(67 \%)$; others had an associate degree $(11 \%)$ or master's degree $(3 \%)$, and one participant had a doctorate degree $(5 \%)$.

Most of the participants were currently employed as a registered nurse (73\%), three of the participants were nurse managers (17\%), one participant was a licensed vocational nurse (5\%), and another participant was a nurse practitioner (5\%). More than half of the study participants had between 1 to 2 national certifications (55\%), and the lesser half had three or more national certifications (45\%). Half of the study participants currently work in pediatric inpatient hospital settings (50\%), some participants work in pediatric outpatient settings (45\%), and one participant works in a setting that is not pediatric based. More than half of the participants identified to be part time workers (55\%), and the rest of the participants identified themselves to be full time workers (45\%). Half of the sample has 10 or less years of experience as a nurse (50\%), five participants had between 11 to 20 years of experience as a nurse (28\%), and four participants had 21 years or more experience as a nurse (22\%). Lastly, a vast majority of the sample had 10 or less years of experience as a pediatric nurse (61\%), five participants had between 11 to 20 years of experience as a pediatric nurse (28\%), and two participants had 21 years or more experience as pediatric nurse $(11 \%)$.

\section{Research Question 1: Education}

Under the first category of the survey instrument, participants were asked to describe their nursing education through multiple questions using a Likert-scale and open-ended questions. The first question in this category asked if the participants felt that their nursing education has 
PSYCHOLOGICAL AND PHYSIOLOGICAL RAMIFICATIONS OF INADEQUATE

PAIN MANAGEMENT AND NURSING PREPARATION

Table 1: Characteristics of the Sample $(n=18)$

\begin{tabular}{|c|c|c|}
\hline Variable & Range & Frequency \\
\hline \multicolumn{3}{|l|}{ Age } \\
\hline & $20-30$ & $(28 \%)$ \\
\hline & $31-50$ & $(50 \%)$ \\
\hline & $51-65$ & $(17 \%)$ \\
\hline & over 65 & $(5 \%)$ \\
\hline \multicolumn{3}{|l|}{ Gender } \\
\hline Female & & $18 \quad(100 \%)$ \\
\hline Male & & $(0 \%)$ \\
\hline \multicolumn{3}{|l|}{ Degree } \\
\hline AA/AS & & $(11 \%)$ \\
\hline BSN & & $12 \quad(67 \%)$ \\
\hline Masters & & $(17 \%)$ \\
\hline Doctorate & & $(5 \%)$ \\
\hline \multicolumn{3}{|l|}{ Current Employment Position } \\
\hline LVN & & $(5 \%)$ \\
\hline RN & & $13 \quad(73 \%)$ \\
\hline Manager & & $(17 \%)$ \\
\hline Nurse Practitioner & & $(5 \%)$ \\
\hline \multicolumn{3}{|l|}{ National Certifications (\#) } \\
\hline & $1-2$ & $10 \quad(55 \%)$ \\
\hline & 3 or more & $(45 \%)$ \\
\hline \multicolumn{3}{|l|}{ Type Unit/Clinical Setting Employment } \\
\hline Pediatric inpatient (hospital) & & $(50 \%)$ \\
\hline Pediatric outpatient (community) & & $(45 \%)$ \\
\hline Other & & $(5 \%)$ \\
\hline \multicolumn{3}{|l|}{ Part Time/Full Time Status Employment } \\
\hline Part Time & & $10 \quad(55 \%)$ \\
\hline Full Time & & $(45 \%)$ \\
\hline \multicolumn{3}{|l|}{ Number of Years Employed as a Nurse } \\
\hline & $1-10$ & $(50 \%)$ \\
\hline & $11-20$ & $(28 \%)$ \\
\hline & 21 or more & $(22 \%)$ \\
\hline \multicolumn{3}{|c|}{ Number of Years Employed as a Pediatric Nurse } \\
\hline & $1-10$ & $11(61 \%)$ \\
\hline & $11-20$ & $5 \quad(28 \%)$ \\
\hline & 21 or more & $(11 \%)$ \\
\hline
\end{tabular}

effectively prepared them to manage pain in pediatrics and the results are as follows (See Figure 1-2). Seven participants agreed with the statement (39\%), four participants felt neutral about the subject matter (22\%), three participants strongly agreed with the statement (17\%), two 
participants disagreed with the statement presented (11\%), and two other participants strongly disagreed with the statement $(11 \%)$. Next, the survey asks the participants to list three key topics that the participants have learned about pain management. Common areas of interests that participants identified as important to learning about pain management included education on different types of pain scales, non-verbal cues of pain, vital signs that correspond with pain, distraction, and pain medications. Then, participants were asked what they felt should have been included in their education regarding pain management and frequent topics included how to mange parent and family involvement, use of alternative treatments, and pain characteristics specified by age group. The last question of this category used a Likert-scale to determine if the participants felt that their nursing education provided them with the ability to learn about psychological aspects of inadequate pain management and the results are as followed (See Figure 2); eight of the participants agreed with the statement (45\%), five of the participants felt neutral about the statement (28\%), three participants disagreed with the statement (17\%), one participant strongly agreed with the statement (5\%), and one other participant strongly disagreed with the statement $(5 \%)$.

\section{Figure 1}

My nursing education has effectively prepared me to manage pain in the pediatric population. Results

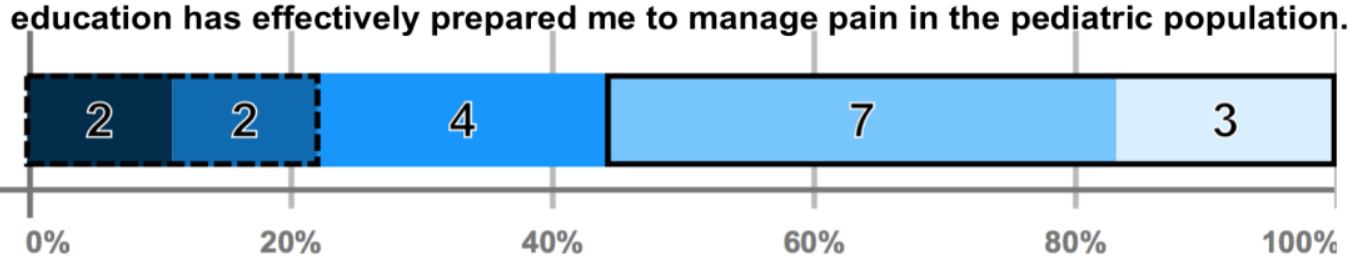

\section{\#1A}

Strongly Disagree

\section{Research Question 2: Professional Development}

Secondly, the next category addresses how participants felt regarding nursing professional development (See Figure 3 and 4). The first question of this category inquires about if participants felt that their nursing education and or nursing administration offers professional 
Figure 2

In your nursing education, did you learn about psychological aspects of inadequate pain management? Results

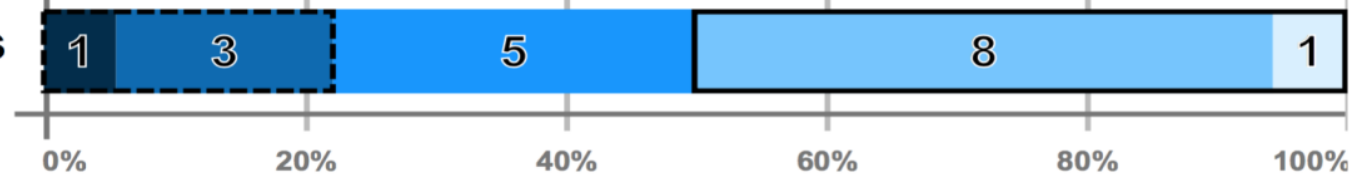

Strongly Disagree

\#1D

Neutral

development regarding pediatric pain management. Nine participants agreed with this statement (50\%), seven participants felt neutral (40\%), one participant strongly agreed with the statement $(5 \%)$, and another participant strongly disagreed with the statement $(5 \%)$. Next, this category goes on to ask an open-ended question asking participants to describe the types of professional development activities they have received. Common types of professional developmental activities participants mentioned included in-service programs, annual competencies, CEUs, workshops, and training sessions. Thirdly, this section asks participants if they felt that their ongoing professional development has included the psychological and physiological aspects of inadequate pain management in pediatrics. Eleven of the participants agreed with the statement (61\%), three disagreed with the statement (17\%), another three strongly disagreed with the statement (17\%), and one participant strongly agreed with the statement (5\%).

\section{Figure 3}

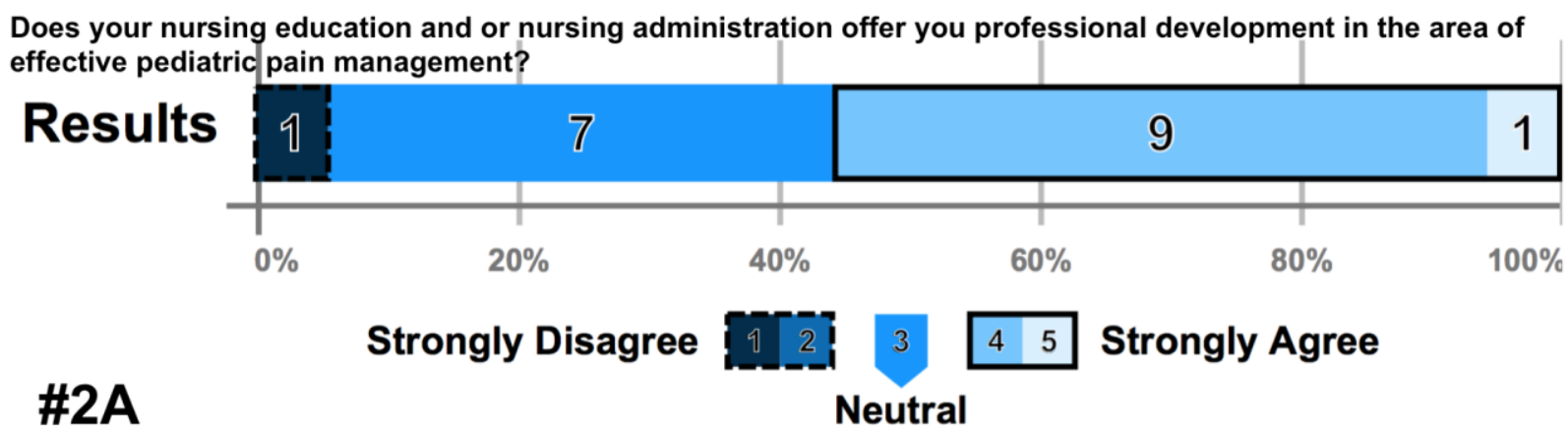

\section{Research Question 3: Inadequate Pain Management}

The third category asks participants about their standpoint on inadequate pediatric pain management. The first portion is a statement that says, "I believe that pain management in the 
pediatric population remains inadequate," and participants were asked to rate how much they

\section{Figure 4}

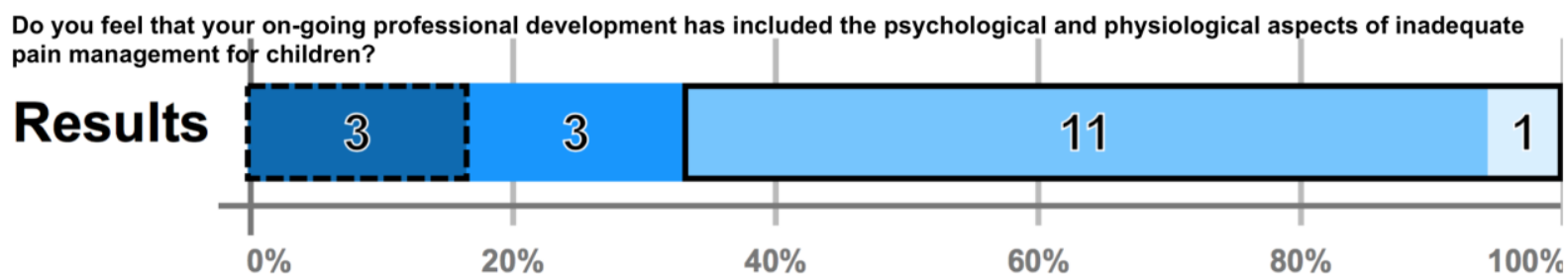

Strongly Disagree

\#2C

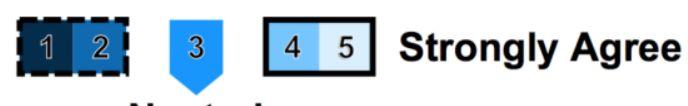
Neutral

agreed with this statement. Eight participants found themselves to feel neutral about this statement (45\%), four participants agreed with this statement (22\%), three participants disagreed with this statement (17\%), two participants strongly agreed with this statement (11\%), and one participant strongly disagreed with this statement (5\%). Then, participants were asked to describe areas they believed contributed to inadequate pediatric pain management. General topics that surfaced from the participants' responses included the lack of continuous and efficient assessment and reassessment, conflict and lack of proper communication with other staff, family, and the patient, inconsistency of prescription's to address patient needs, underuse and fear of using pharmacological interventions to manage pain, and inadequate staffing and timing availability.

\section{Figure 5}

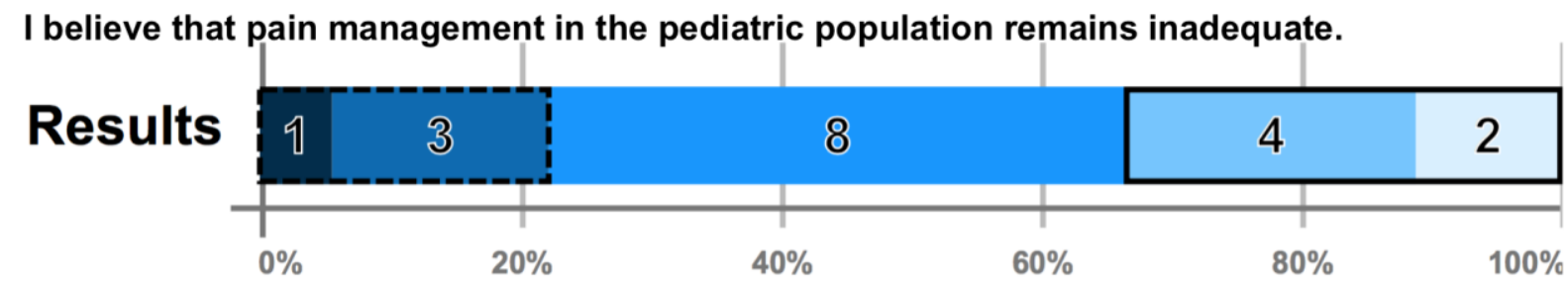

\section{\#3A}

Strongly Disagree

\section{Research Question 4: More Educational Resources}

Fourthly, the next category focuses on availability of educational resources to the 
participants. In the first portion of this category a statement is presented, "I believe that more educational measures are needed to support pain management in the pediatric population." Eight participants agreed with the statement (45\%), four participants strongly agreed with the statement (22\%), another four participants felt neutral about the statement (22\%), one participant disagreed with the statement (5\%), and another participant strongly disagreed with the statement (5\%). Next, participants were asked to list three topics for further educational offering and common subjects including the following: management and understanding of chronic pain in pediatrics and emotional and mental support for pain management addressing stress, anxiety, fear, and relaxation.

\section{Figure 6}

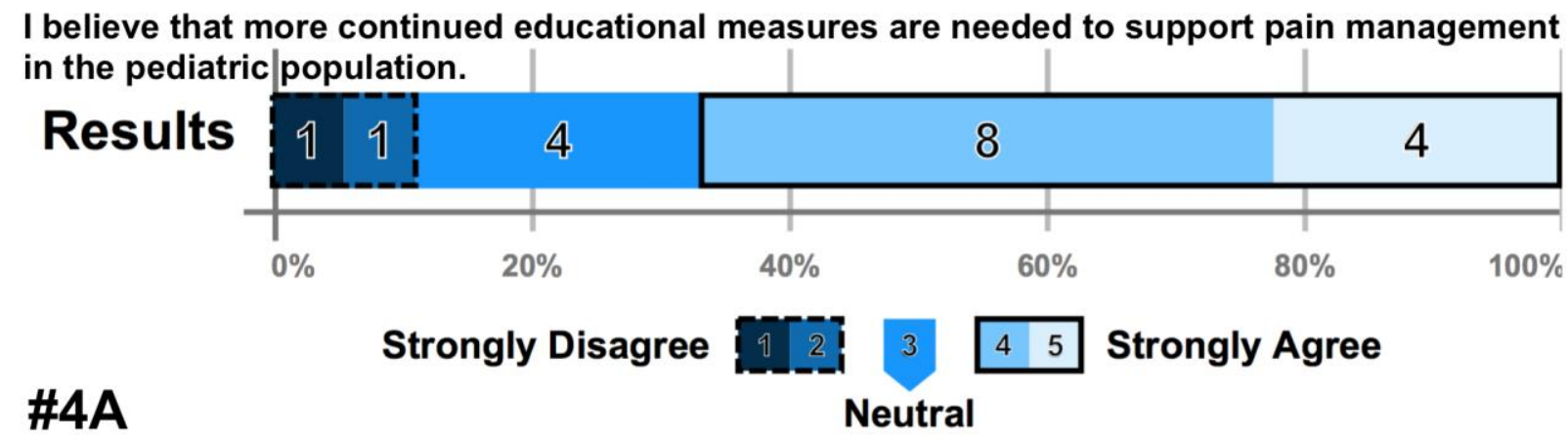

\section{Research Question 5: Knowledge}

The fifth category addresses nursing knowledge related to pediatric pain management. Of the statement, "I believe that my knowledge as a nurse is satisfactory to support pediatric pain management," over half of the participants acknowledged agreement with this statement (72\%). Additionally, four participants agreed with the statement (22\%) and one participant felt neutral about the statement (5\%). None of the participants felt that they disagreed or strongly disagreed with this statement.

\section{Research Question 6: Self-Efficacy}

The last category addresses nurses' self-efficacy regarding pediatric pain management. This statement was presented to the participants, "I believe that my self-efficacy as a nurse is 
satisfactory to support pediatric pain management." More than half of the participants agreed

Figure 7

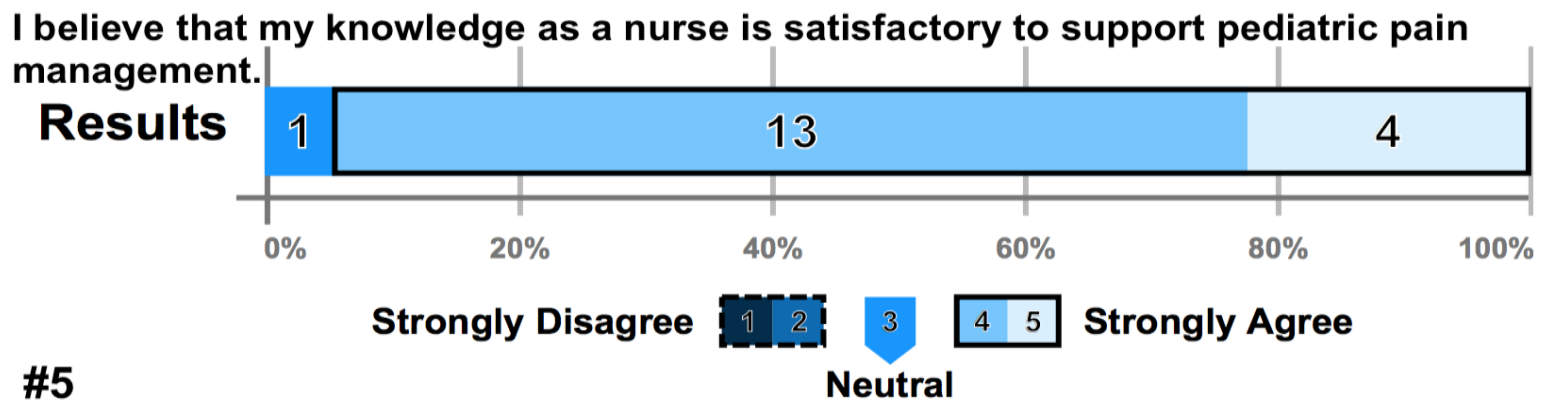

with this statement (67\%) and six participants strongly agreed with this statement (33\%). None of the participants found themselves to disagree or strongly disagree with the statement.

\section{Figure 8}

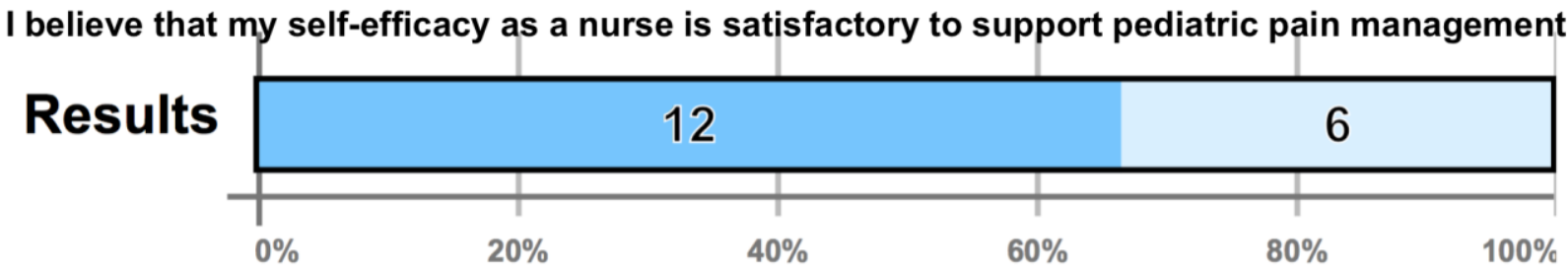

\section{\#6}

Strongly Disagree

$4 \quad 5$ Strongly Agree

\section{Neutral}

\section{Discussion}

The comprehensive purpose of this study was to assess the psychological and physiological ramifications of inadequate pain management through investigating the influences of nursing preparation. This study was able to examine how nurses felt about their nursing professional preparation, and their collective responses presented to be consistent throughout, while also shedding light onto similar areas of inadequate pediatric pain management that show significance in terms of being addressed.

A majority of nurses felt that both their educational and professional development of pediatric pain management prepared them to handle pediatric pain management. It is noted that more than half of the nurses felt that their professional development provided them with some 
sort of support to effectively manage pediatric pain management. Types of professional activity that participants mentioned more than once include inservices, annual competencies, continuing education units, workshops, and training sessions. In addition, more than half of the participants agreed that their professional development provided them with information related to psychological and physiological effects of inadequate pain management. Factors that affect and are caused by inadequate pediatric pain management are consistently present in nurses' professional development, but adding thorough details of this topic needs to be continuously incorporated into their professional development as well.

However, a little under half of the participants felt their nursing education prepared them enough to handle pediatric pain management but participants more so agreed with this than disagreed. In terms of education, participants mentioned these topics more than once as important pointers, different pain scales, non-verbal cues, vital signs, distraction, and pain medications. Topics that participants agreed upon that were important but not addressed during their nursing education included how to manage parent and family involvement, use of alternative treatments, and pain characteristics related to specific age groups. Overall, based on the participants' responses, there are multiple areas that need to be included in nursing education to cover the complexity of nursing knowledge necessary to manage pediatric pain management. In addition, although nursing education does provide different areas of knowledge to understand pediatric pain management, there are always more topics that can be added to the nursing education to continuously support and keep up to date with managing pediatric pain.

In terms of how nurses felt about the current status of inadequate pediatric pain management, less than half but more so than not, most participants felt neutral about inadequate pain management existing today. Possibly, further research should look into investigating why nurses feel neutral about this subject matter and whether or not its based on personal feelings, or 
accounted for with experience or other validating factors. Although participants felt neutral about the subject matter, they presented that multiple factors contributed to inadequate pain management including lack of efficient and continuous assessment and reassessment, parental control, communication barriers between staff, family, and patient, fear of medications and underuse of medications, lack of appropriate prescriptions, and short staff and lack of time availability.

Next, participants agreed more than disagreed that more educational resources were necessary to support adequate pediatric pain management. Topics listed by participants about additional education resources that should be addressed included management and understanding chronic pain in pediatrics and mental and emotion support of the patient related to anxiety, fear, stress, and relaxation.

Lastly, more than half of the participants agreed that both their level of knowledge and self-efficacy as a nurse is satisfactory enough to support pediatric pain management. This finding needs to be further investigated with a form of measurement that would investigate how nurses felt about their satisfactory ability to support pediatric pain management matched up with definitive results. Overall, nurses had a positive outlook on how they provide care regarding pediatric pain management.

The information provided through this study remained fairly consistent throughout. It must be noted that limitations also existed in this study. Firstly, the small sample size may be inaccurate to represent the perspective of the entire population of pediatric nurses and their outlook on pediatric pain management, but provides a starting point on weaknesses and strengths related to the subject matter. Secondly, the study unintentionally consisted of all female participants. Further research of this topic should be addressed that includes male participants, as gender may play a role in possibly affecting the pediatric nursing perspective on pain 
management.

The pain experience in the pediatric population is inevitably a dynamic process that pediatric nurses will continuously be faced with. To further support attempting to resolve and relieve pediatric patients with high quality care of their pain, research must by directed at looking into the strengths and weaknesses that influence the nursing professional development in pediatric pain management. Collaborative effort between nurses with other nurses and other healthcare professionals in general is vital to successfully supporting pediatric pain management. Pain is not an easy concept to address, however, the challenges it comes with can further be managed with improving relationships between pediatric nurses and the patient and family. This is especially important because pediatrics is focalized on family-centered care, which makes it unique compared to other specialties in nursing. 


\section{References}

American Academy of Pediatrics, American Pain Society, Committee on Psychosocial Aspects of Child and Family Health, Task Force on Pain in Infants, Children, and Adolescents. (2001). The Assessment and Management of Acute Pain in Infants, Children, and Adolescents. Retrieved from http://pediatrics.aappublications.org/content/pediatrics/108 13/793.fu 11.pdf

American Nurses Association. (2001). Code of ethics for nurses with interpretive statements. Washington, D.C: American Nurses Association.

Bahorski, J. S., Hauber, R. P., Hanks, C., Johnson, M., Mundy, K., Ranner, D., . . Gordon, G. (2015). Mitigating procedural pain during venipuncture in a pediatric population: A randomized factorial study. International Journal of Nursing Studies, 52(10), 15531564. Doi:http://dx.doi.org.ezproxy.dominica n.edu/10.1016/j.ijnurstu.2015.05.014

Bice, A. A., Gunther, M., \& Wyatt, T. (2014). Increasing nursing treatment for pediatric procedural pain. Pain Management Nursing, 15(1), 365-379.doi:http://dx.doi.org/1 0.1016/j.pmn.2012.06.004

Brennan, F., Carr, D. B., \& Cousins, M. (2007). Pain management: A fundamental human right. Anesthesia and Analgesia, 105, 205-221. doi: 10.1213/01.ane.000 268145.52345.55

Cotton Sian, Luberto Christina M., Bogenschutz Lois H., Pelley Terri J., and Dusek Jeffrey. Integrative Care Therapies and Pain in Hospitalized Children and Adolescents: A Retrospective Database Review. The Journal of Alternative and Complementary Medicine, 20, 98-102. doi:10.1089/acm.2013.0306.

Hockenberry, Marilyn, David Wilson. Wong's Essentials of Pediatric Nursing, 9th Edition. Mosby. VitalBook file.

International Association for the Study of Pain, Special Interest Group on Pain in Childhood 
(2005). Children's Pain Matters! Priority on Pain in Infants, Children, and Adolescents.

Retrieved from http://www.iasp-pain.org/AM/Template.cfm?Section=2005_2006_Pain_

in_Children1\&Template=/CM/ContentDisplay.cfm\&ContentID=2993

Giddens, Jean (2012). Concepts for nursing practice. Mosby, 032012. VitalBook file.

theory.org/

Kozlowski, L. J., Kost-Byerly, S., Colantuoni, E., Thompson, C. B., Vasquenza, K. J., Rothman, S. K., . . Monitto, C. L. (2014). Pain prevalence, intensity, assessment and management in a hospitalized pediatric population. Pain Management Nursing, 15(1), 22-35.

doi:http://dx.doi.o rg.ezproxy.dominican.edu/10.1016/j.pmn.2012.04.003

LaFond, C. M., Van Hulle Vincent, C., Oosterhouse, K., \& Wilkie, D. J.Nurses' beliefs regarding pain in critically ill children: A mixed-methods study. Journal of Pediatric Nursing, doi:http://dx.doi.org/10.1 016/j.pedn.2016.08 .002

Miró, J., Huguet, A., \& Jensen, M. P. (2014). Pain beliefs predict pain intensity and pain status in children: Usefulness of the pediatric version of the survey of pain attitudes. Pain Medicine, 15(6), 887-897. doi:10.1111/pm e.12316

O'Neal, K., \& Olds, D. (2016). Differences in pediatric pain management by unit types. Journal of Nursing Scholarship, 48(4), 378-386. doi:10.1111/jnu .12222

Petiprin, Alice. Jean Watson nursing theory. (2016). Nursing Theory. Retrieved from http://www.nursing-theory.org

Stevens, B. J., Yamada, J., Estabrooks, C. A., Stinson, J., Campbell, F., Scott, S. D., \& Cummings, G. (2014). Pain in hospitalized children: Effect of a multidimensional knowledge translation strategy on pain process and clinical outcomes. Pain $®, 155(1)$, 60-68. doi:http://dx.d oi.org.ezproxy.dominican.edu/10.1016/j.pain.2013.09.007

Stanley, M., \& Pollard, D. (2013). Relationship Between Knowledge, Attitudes, and SelfEfficacy of Nurses In the Management of Pediatric Pain. Pediatric Nursing, 39, 165- 
171. Retrieved from https://www.pediatricnursing.net/

-Twycross, A. (2007). Children's nurses' post-operative pain management practices: An observational study. International Journal of Nursing Studies, 44(6), 869-881. doi:http:/ doi:http://dx.doi.o rg/10.1016/j.ijnurstu.2006.03.010

Twycross, A. (2011). Nurses' views about the barriers and facilitators to effective management of pediatric pain. Pain Management Nursing, 14(4), e164-e172. doi: http://dx.doi.org/ 10.1016/ j.pmn.2011.10.007

Zisk-Rony, R. Y., Lev, J., \& Haviv, H. (2015). Nurses' report of in-hospital pediatric pain assessment: Examining challenges and perspectives. Pain Management Nursing, 16(2), 112-120. doi:http://dx.doi.org/10.1016/j.pmn.2014.05.003 


\section{APPENDIX A \\ LETTER OF INTRODUCTION TO STUDY PARTICIPANTS}

Dear Study Participant,

My name is Genica-Jade Ocampo and I am an undergraduate Nursing major at Dominican University of California. I am conducting a research project as part of my senior thesis requirements, and this work is being supervised by Dr. Luanne Linnard-Palmer, RN, EdD, Professor of Nursing at Dominican University of California. I am requesting your voluntary participation in my study, which concerns the influence of nursing preparation on the physiological and psychological ramifications of inadequate pain management for the pediatric population.

Participation in this study involves completion of a paper copy or online version of a survey regarding education and professional nursing preparation of pediatric pain management, personal experiences and values of pediatric pain management, as well as some demographic questions to be used for statistical purposes. Please note that your participation is completely voluntary and you are free to withdraw your participation at any time. Likewise, your participation or non-participation will not affect your employment, as location of employment will be left out of this study. In addition your survey responses are designed to be completed anonymously. Anonymity cannot be guaranteed, however, and in the unlikely event an identity becomes known, all information will be held as completely confidential. Aside from anonymous submissions of surveys either in person or via online, filling out the survey is likely to take approximately 15 minutes of your time.

If you choose to participate in this study, please fill out the attached materials as honestly and completely as possible. You will only be required to submit one form of admission, either the paper copy or the online survey. For distribution of the paper copy, I will provide participants with the paper copy survey directly in person, and will come back to the area of dropped off surveys within two weeks after administration to pick up the completed and anonymous surveys. For surveys taken via online, it will be sent out with a link via email with a designated time when the participants may start the survey, and will be provided with a deadline for submission.

Remember, this survey is completely anonymous; do not put your name or any other identifying information on your survey form.

If you have questions about the research you may contact me at the email address below. If you have further questions you may contact my research supervisor, Dr. Luanne Linnard-Palmer via email luanne.linnard-palmer@ dominican.edu, or through telephone call via (415)-257-1364, or through calling the Dominican University of California Institutional Review Board for the Protection of Human Participants (IRBPHP), which is concerned with protection of volunteers in research projects. You may reach the IRBPHP Office by calling (415) 482-3547 and leaving a voicemail message, or FAX at (415) 257-0165, or by writing to IRBPHP, Office of Associate Vice President for Academic Affairs, Dominican University of California, 50 Acacia Avenue, San Rafael, CA 95901.

If you would like to know the results of this study once it has been completed, a summary of the results will be presented at Dominican University of California's Academic Showcase in April 2017. Contact me at the email address below for further information.

Thank you in advance for your participation as this will serve as a major contribution to my growth in the nursing profession,

Sincerely,

Genica-Jade Cruz Ocampo, N.S.

Nursing Department

Dominican University of California

50 Acacia Avenue

San Rafael, CA 94901

Email address: [genica-jade.ocampo@students.dominican.edu] 


\author{
APPENDIX B \\ LETTER OF CONSENT TO AGENCY DIRECTORS \\ DOMINICAN UNIVERSITY of CALIFORNIA \\ LETTER OF PERMISSION TO DIRECTOR OF MY FRIENDS PEDIATRIC DAY HEALTHCARE \\ CENTER
}

\author{
Monica Bausino \\ Director of My Friends \\ 2288 Lincoln Ave \\ San Jose, CA 95125
}

Dear Mrs. Monica Bausino:

This letter confirms that you have been provided with a brief description of my senior thesis research project, which concerns influences of professional nursing preparation on inadequate pain management in the pediatric population, and that you give your consent for me to visit your facility to drop off paper copy surveys for nursing staff to voluntary participate, and the completed surveys will be directly picked up by me two weeks after initial drop off of surveys. This project is an important part of my undergraduate requirements as a Nursing major, and is being supervised by Dr. Luanne Linnard-Palmer, Professor of Nursing at Dominican University of California.

As we discussed in person, I will make every effort to ensure that my data collection does not interfere with your regularly scheduled appointments and working hours, and that your clients are treated with the utmost discretion and sensitivity. If you have questions about the research you may contact me at phone number or email address below. If you have further concerns you may contact my research supervisor, Dr. Luanne Linnard-Palmer, at (415)-257-1364 or the Institutional Review Board for the Protection of Human Participants at Dominican University of California by calling (415) 482-3547.

After my research project has been completed in May 2017, I will be glad to send you a summary of my research results.

If my request to visit your establishment and to provide surveys for the nursing staff to voluntary participate meets with your approval, please sign and date this letter below, and I will directly pick up this form from you. Please feel free to contact me if you have any questions about this project.

Thank you very much for your time and cooperation as you are supporting my growth in my nursing education,

Sincerely,

Genica-Jade Ocampo

Dominican University of California

50 Acacia Avenue

San Rafael, CA 94903

Email address: [genica-jade.ocampo@students.dominican.edu]

(707)246-7701

I agree with the above request 


\section{APPENDIX B LETTER OF CONSENT TO AGENCY DIRECTORS DOMINICAN UNIVERSITY of CALIFORNIA LETTER OF PERMISSION TO NURSING STAFF OF TAMALPAIS PEDIATRICS}

Elizabeth Abell

Tamalpais Pediatrics

400 Professional Center Dr.

Novato, CA 94947

Dear Mrs. Elizabeth Abell:

This letter confirms that you have been provided with a brief description of my senior thesis research project, which concerns influences of professional nursing preparation on inadequate pain management in the pediatric population, and that you give your consent for me to visit your facility to drop off paper copy surveys for nursing staff to voluntary participate, and the completed surveys will be directly picked up by me two weeks after initial drop off of surveys. This project is an important part of my undergraduate requirements as a Nursing major, and is being supervised by Dr. Luanne Linnard-Palmer, Professor of Nursing at Dominican University of California.

As we discussed in person, I will make every effort to ensure that my data collection does not interfere with your regularly scheduled appointments and working hours, and that your clients are treated with the utmost discretion and sensitivity. If you have questions about the research you may contact me at phone number or email address below. If you have further concerns you may contact my research supervisor, Dr. Luanne Linnard-Palmer, at (415)-257-1364 or the Institutional Review Board for the Protection of Human Participants at Dominican University of California by calling (415) 482-3547.

After my research project has been completed in May 2017, I will be glad to send you a summary of my research results.

If my request to visit your establishment and to provide surveys for the nursing staff to voluntary participate meets with your approval, please sign and date this letter below, and I will directly pick up this form from you. Please feel free to contact me if you have any questions about this project.

Thank you very much for your time and cooperation as you are supporting my growth in my nursing education,

Sincerely,

Genica-Jade Ocampo

Dominican University of California

50 Acacia Avenue

San Rafael, CA 94903

Email address: [genica-jade.ocampo@students.dominican.edu]

(707)246-7701

\section{I agree with the above request}




\title{
APPENDIX B LETTER OF CONSENT TO PRESIDENTS OF NURSING ORGANIZATIONS
}

\author{
*(Content of Email) Nurses Society \\ Dear
}

My name is Genica-Jade Ocampo and I am an undergraduate Nursing major at Dominican University of California. I am conducting a research project as part of my senior thesis requirements, and this work is being supervised by Dr. Luanne Linnard-Palmer, RN, EdD, Professor of Nursing at Dominican University of California. I am requesting your permission to acquire participants for my study through members of your organizations. My research study concerns the influence of nursing preparation on the physiological and psychological ramifications of inadequate pain management for the pediatric population. With your approval I would like to request access to send a group email to your member with the opportunity to participate in my study by attaching the purpose of my study, and the survey link to my study. I would greatly appreciate your approval and support.

The purpose of this email is to acquire your consent for me to email members of Sigma Theta Tau Rho Alpha Chapter with the opportunity to complete my survey with a provided online link. This project is an important part of my undergraduate requirements as a Nursing major, and is being supervised by Dr. Luanne Linnard-Palmer, Professor of Nursing at Dominican University of California. Please see the attached link of an example of my survey.

Every effort will be taken to ensure that my data collection does not interfere with your organization and members in terms of confidentiality, and that your clients are treated with the utmost discretion and sensitivity. If you have questions about the research you may contact me at phone number or email address below. If you have further concerns you may contact my research supervisor, Dr. Luanne Linnard-Palmer, at (415)-257-1364 or the Institutional Review Board for the Protection of Human Participants at Dominican University of California by calling (415) 482-3547.

After my research project has been completed in May 2017, I will be glad to send you a summary of my research results.

If my request to contact your members and provide them with my survey link to complete has your consent, please reply back with a confirmation email that you approve and will assist me in reaching out to the members of your organizaion. Please feel free to contact me if you have any questions about this project.

Thank you very much for your time and cooperation.

Genica-Jade Ocampo

Dominican University of California

50 Acacia Avenue

San Rafael, CA 94903

Email address: [genica-jade.ocampo@students.dominican.edu]

(707)246-7701 


\section{DOMINICAN \\ UNIVERSITY \\ of CALIFORNIA \\ 1890}

Professional Nursing Preparation and Pediatric Pain Management Survey

Demographics

$\begin{array}{lllll}- & \text { Age (circle one): } \quad 20-30 & 31-50 & 51-65 & \text { over } 65\end{array}$

- Gender: Male Female Do not wish to disclose

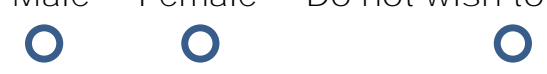

Highest Degree of Education:

Current Employment Position:

National Certifications:

Type of Unit/Clinical setting of Employment:

Part Time or Full Time Status:

Number of Years Employed as a Nurse:

Number of Years Employed as a Pediatric Nurse:

Please FILL IN the following selections below, strongly agree, agree, neutral, disagree, or strongly disagree for each of the following questions:

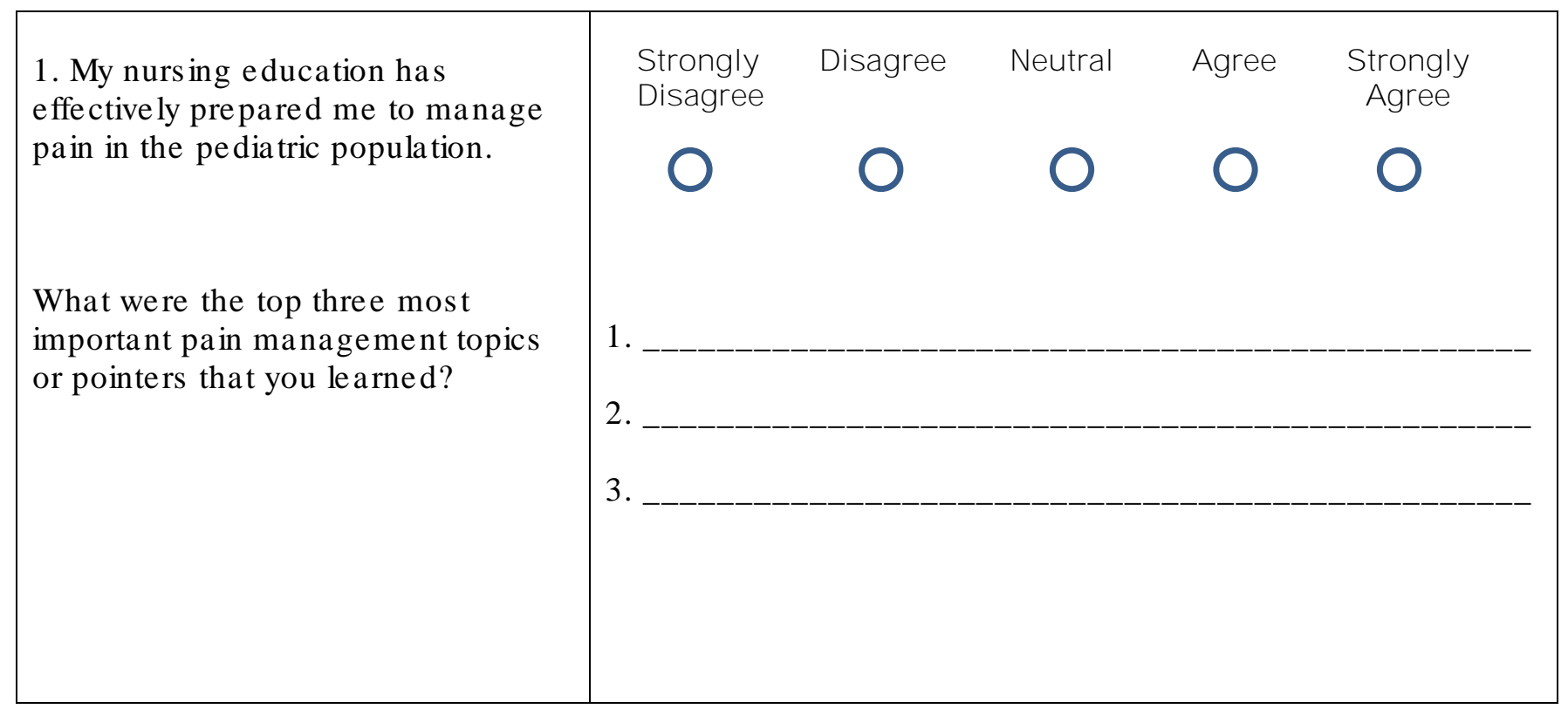




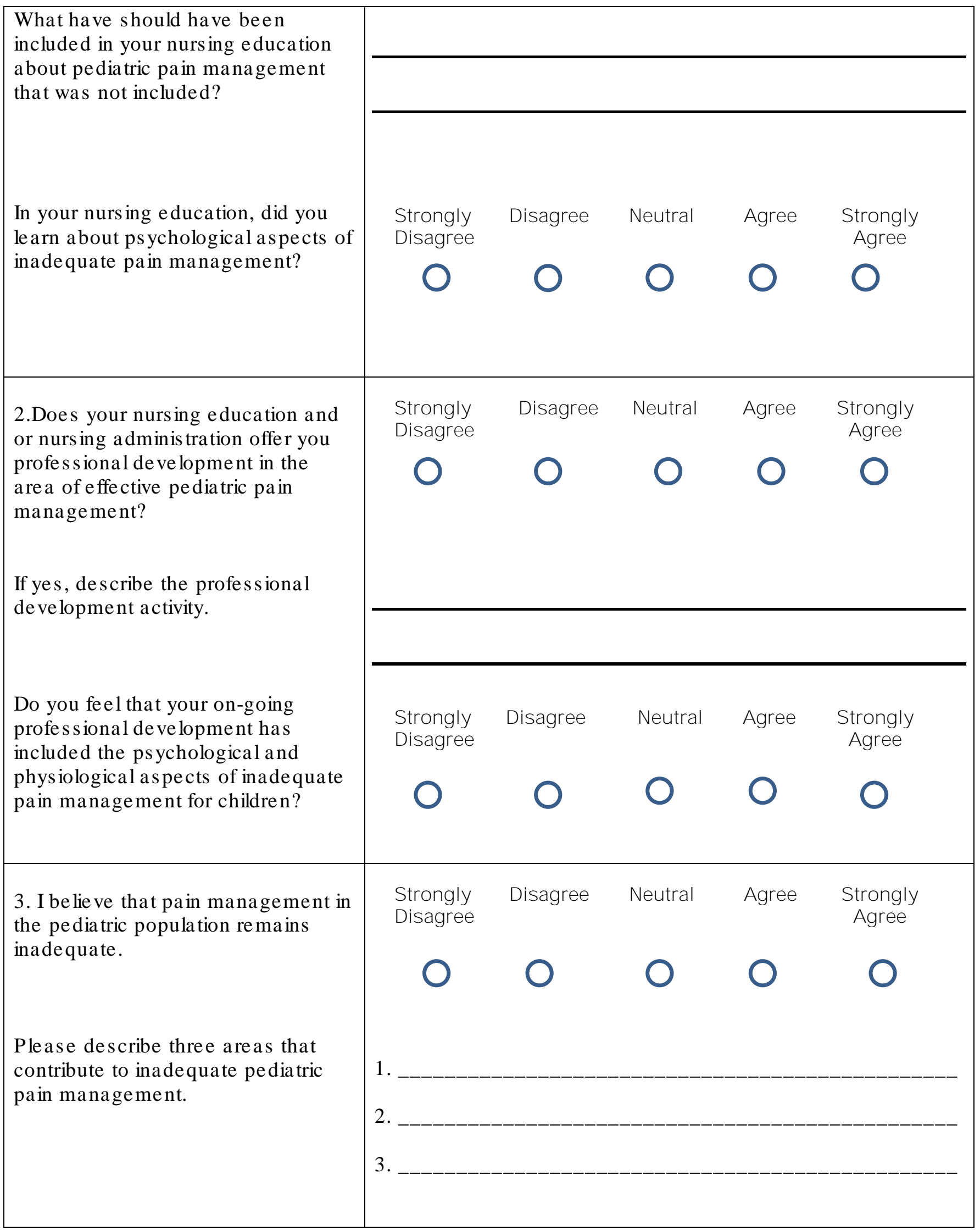


PAIN MANAGEMENT AND NURSING PREPARATION

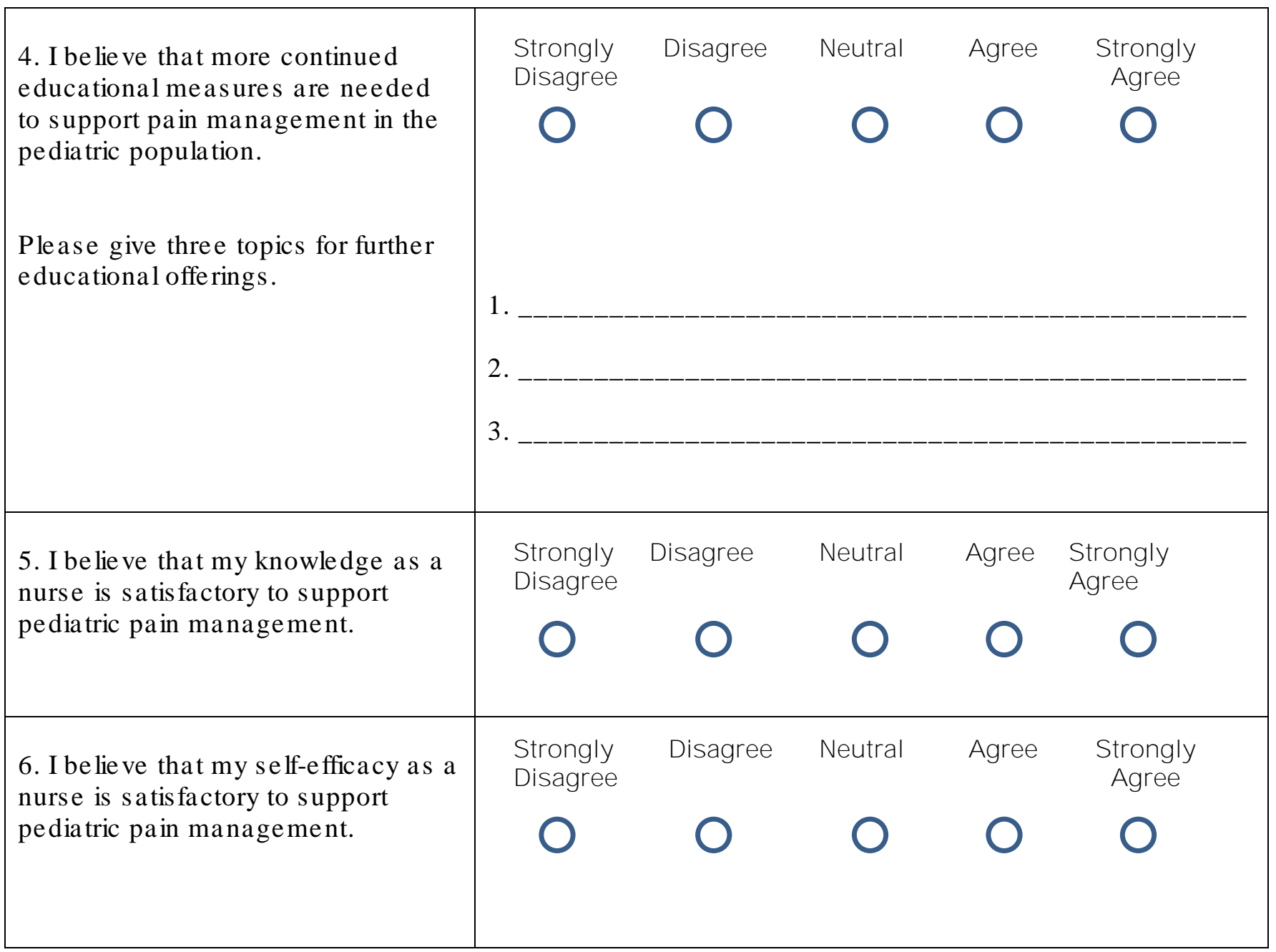

